\title{
Empirical Study of the Factors which Have an Impact on University Performance in EU Countries, Reflected by the Shanghai Ranking
}

\author{
Olga POP \\ Technical University of Cluj-Napoca, Romania \\ olga.savciuc@staff.utcluj.ro \\ Sorin POPESCU \\ Technical University of Cluj-Napoca, Romania \\ sorin.popescu@muri.utcluj.ro \\ Mihai DRAGOMIR \\ Technical University of Cluj-Napoca, Romania \\ mihai.dragomir@muri.utcluj.ro
}

\begin{abstract}
The study tries to prove the existence of a significant relationship between EU countries academic excellence measured by international university rankings scores and the level of attainment for the EU strategic objectives in higher education and research, as are measured by the countries' values of the afferent indicators. The study was applied to the correlation between some headline indicators of the Europe 2020 strategy and the Shanghai Ranking scores. Measuring the strength of a linear association between variables by using the Pearson Correlation, a strong correlation was found between the country Shanghai scores and the country values for indicators such as: "public expenditure in education", "expenditure in R\&D", "patent stock", and "lifelong learning". A moderate correlation with students' international mobility was also identified.
\end{abstract}

Keywords: university rankings, academic excellence, higher education and research excellence, Europe 2020 indicators, Shanghai Ranking.

\section{INTRODUCTION}

In a world where knowledge became the main resource, higher education and research are crucial activities and the universities are main actors in a competitive economy. In such a context, for policy makers, the investment in education and research should be present as a high priority in achieving a sustainable growth (UNESCO, 2015) while for universities, to target society wellbeing should become the main component of their mission. 
From the decision bodies side, this holds true for most of the countries, on all continents, and a special focus is placed on it in the countries of the European Union (EU), which has become one of the largest economic areas of the world. At the beginning of this decade, the European Commission has brought to light "Europe 2020" (EC, 2010) a programmatic framework to support the implementation of its growth strategy. As part of it, the EC proposed a set of higher education and research objectives for the EU countries, sustained by coherent policies and measured by specific indicators. At the same time, on the universities' side, they are more concerned with "excellence" expressed as visibility. Public and scientific acknowledgments as: academic prize, titles, publications and citations are quantified and encouraged more as bridging the knowledge gap between research and economy.

The Academic Ranking of World Universities, ARWU or Shanghai Ranking, started in 2003 as an exercise of a research team from Shanghai Jiao Tong University in China, was initially intended to establish the standing of Chinese universities internationally following the launch of a government initiative to create world-class universities (The Guardian, 2013). ARWU had a butterfly effect (Hazelkorn, 2015) both on the academic and stakeholders' worlds. As in other cases, this exercise demarche, becoming popular, has passed from the wing fluttering of a butterfly to the storm of a lot of university rakings promoted by international, national bodies, private companies and newspapers, being integrated by universities and policy makers in their strategic frameworks and followed by the public as representing academic quality. Each ranking measures university performance through different indicators connected generally to the academic recognition of research and education such as: international prizes, publications and citations, etc. Some are using also surveys collecting the feed-back of the stakeholders from society.

Very popular, strongly praised and criticised by different specialists and stakeholders, university rankings brought up at the same time significant questions concerning their correlation with the society's long term objectives. Some assumptions can be made, but it is rather impossible to determine in a reliable way the impact of universities' positions in these rankings on the economic and social wellbeing of the areas they serve.

This paper place its intentions in an opposite approach: to establish if there is a certain correlation between the main indicators for education and research in the EU 2020 Strategy and academic excellence measured by ARWU (currently the most popular university ranking). In other words, the research intends to determine the degree in which the increasing of the mentioned indicators will also have a significant impact on the EU universities' positions in the ARWU ranking.

\section{ACADEMIC QUALITY, EXCELLENCE AND RANKINGS}

Quality became a much debated subject in the academic field in the first decades of this century as it was 20 years earlier in the economic domain, where now it has reached its maturity. This attention given to the teaching and research quality in universities is coming mainly under the pressure exercised, on one hand, by the society for university 
accountability and, on the other hand, by the competitive attitude created and encouraged by globalisation within the international higher education and research environment. The first pressure has led to accreditation as an institutional answer meant to check the conformance of academic activity to minimal standards while the second one found its representation in academic rankings, homologous to the excellence models and quality prizes in the economic environment.

University ranking systems are built upon "some combination of institutional performance, institutional characteristics, and other factors" (Shin \& Toutkoushian, 2011, p. 6) that, after being evaluated, allow the listing of academic institutions in a descending order, highlighting the best placed from those points of view. Rankings were facilitated by the increasing amount of information available on the world wide web about the activity and results of universities and the facilities to access and process that information but also to disseminate it. "University league tables which compare the performance of different institutions have been advocated as a potentially efficient and effective means of providing needed information" (Dill \& Soo, 2005, p. 525) for consumers (students, policymakers, etc.). In the following, a brief characterisation of some of the main world academic rankings is presented. It is not an exhaustive one, as it could be completed by other numerous international, national and domain specific university rankings.

The already mentioned Academic Ranking of World Universities ARWU, is focused on measuring especially research performances. For that purpose it uses indicators (CWCU, 2013) connected to alumni and staff winning Nobel Prizes and Fields Medals, highly cited researchers, papers published in the journals Nature and Science, papers indexed in major citation indices, and the per capita academic performance of an institution.

QS World University Ranking has started in 2004 as combination of QS (Quacquarelli Symonds) and THE (Times Higher Education). The partnership has ended in 2009 and, from 2010, QS is promoting this ranking alone. It is based on six performance indicators designed to assess universities through four perspectives: research, teaching, employability and internationalization (QS, 2015) by collecting information from both public databases and global surveys of academics and graduate employers. QS allows for the ranking deployment on regions or countries (worldwide), as well as on topics, highlighting best institutions in five broad areas and in 36 individual subject areas.

The THE Thomson Reuters world academic ranking methodology (Times Higher Education, 2015) focuses on: teaching, research, knowledge transfer and international outlook and employs 13 calibrated performance indicators. There is a significant emphasis on research (research connected indicators $>60 \%$ ). The novelty is the extension named "most innovative universities" list based on four indicators established starting from university-industry collaborations.

The Ranking Web or Webometrics is performed from 2004 by the Cybermetrics Lab (Cybermetrics Lab, 2015) and provides information about the performance of universities based on their web presence and impact. The ranking is built from publicly available web data, and it measures three indicators: university web presence, visibility and web access. 
U-Multirank assumes to be a "multi-dimensional, user-driven" approach to international ranking of universities. It was prepared with EU funding by CHERPA, a consortium of European institutions including the "Center for Higher Education Policy Studies" (CHEPS) from the Netherlands and the "Centre for Higher Education" (CHE) from Germany (ECCHERPA, 2014). Its ranking criteria are: teaching and learning, research, knowledge transfer, international orientation and regional engagement. The information is supplied by institutions, extracted from international bibliometric and patent databases and collected by surveys of students. Based on these data, U-Multirank allows the comparison of institutions with similar profiles and allows users to develop personalized rankings by performance indicators, geographical region or scientific area.

Even if its intended result is not a university ranking, the "Composite Indicator for Scientific and Technological Research Excellence" introduced by European Commission in 2013 (EC, 2013) can be used to rank countries by their levels of research excellence and integrates rankings of institutions. Elaborated by an "Expert group" formed in 2011, the "composite indicator" evaluates the research excellence based on four indicators: highly cited publications (Scopus 10\% most highly cited publications where at least one author is affiliated to the given country), top scientific universities and public research organizations (calculated in relation to a country's population, per million inhabitants based on top 250 universities and top 50 public research institutions in the Leiden Ranking respectively in the Scimago Institutional Ranking), patent applications (counts patents that are registered in multiple countries under the Patent Cooperation Treaty PCT), and value of ERC (European Research Council) grants received divided by public R\&D spending performed by the higher education and government sectors.

(Hardeman, Van Roy, \& Vertesy, 2014), an interesting review of European approaches to academic excellence, consider the Composite indicator as a mature approach to research excellence and argue that "excellence should be seen in the context of the knowledgebased economy" (p. 3). The authors of the present paper have a similar understanding in this matter and within their contribution they try to emphasize that between economic strategies and excellence approaches there is a significant correlation even if that is not declared as an explicit intention.

\section{RESEARCH METHODOLOGY}

To achieve the mention purpose, this paper will analyse the relationship between university performance of each country from European Union (EU27) that has at least one ranked university in the Shanghai 500 classification, plus Norway, Turkey and Croatia, and a set of indicators connected with Higher Education and research modernization chosen from the EU targets deployed from the Europe 2020 strategy. The research supposed (statistic alternative hypothesis) that these variables will be significantly correlated with the national Shanghai scores.

The collected data for the present research were placed in 2 consecutive years: 2010 being the Europe 2020 strategy launching year and 2011, used for results redundancy / 
confirmation. As statistic tool, the Pearson correlation was used, the correlation coefficient $r$ validating the hypothesized linear relationship between two variables " $x$ " and " $y$ " in terms of strength and direction. In our case, the dependent variable was " $y=$ country score", and the independent variable was " $x=$ country values" for the chosen indicators. The three steps of the research methodology will be briefly presented in the following.

The first step will describe the method of determining the Shanghai scores for each country. Each university from the Top 500 Shanghai Ranking has a final overall score that is obtained when we divide each institutional score to the highest scoring institution, which is a score of 100. In such a way, the best institution will have score equal to 1 , and the other universities' scores will be $<1$. For each country, we then compute the sum of Top 500 Shanghai ranked institutions that belong to this country, and divide the sum by the country's population.

The second step includes the rationales for the independent variables selection. From the Europe 2020 strategy the intention was to take into consideration only indicators which are relevant to higher education and research. In our case, for higher education there were selected (Eurostat, 2015a) the following indicators: Public expenditure on education, Tertiary educational attainment (counted by graduates aged 30-34 years), Student mobility in tertiary education (measured by international students) and Lifelong learning, while from the $\mathrm{R} \& \mathrm{D}$ indicators (Eurostat, 2015b) there were included in the research: $R \& D$ expenditure and Patents. The selection of the mentioned variables was based more on data availability for each country and for the studied period. If, in the case of education, the choice satisfies also the condition of relevance, for the research case some indicators relevant for excellence (e.g. EU funding for research and innovation, Innovation performance) have been avoided for reasons of momentarily access to information. Normally, in the authors' opinion, this does not affect the research results regarding the stated research hypothesis. If there will be a confirmation for the majority of chosen indicators, it is reasonable to extend the answer for other connected indicators or for most of them.

The third step includes the calculation method of the correlation coefficient and its interpretation. For each year and indicator, the set of country values, was represented in a scatter plot that correlates these values with the Shanghai ranking country scores for the same year. For exemplification, the scatter plot for the 2010 correlation between EU countries' R\&D expenditure and their Shanghai ranking scores is shown in figure 1. For calculation of the Pearson correlation coefficient $r$ and for determining the significance level p-values, the SPSS software was used. As interpretation intervals there were considered: low correlation for $r \in(0-0.29)$; moderate correlation for $r \in(0.3-0.49)$ and strong correlation for $r \in(0.5-1)$. If the $\mathrm{p}$-value is not less than the significance level $(\alpha=0.05)$ it was considered that there is insufficient evidence to conclude there is a significant linear relationship between $\mathrm{x}$ and $\mathrm{y}$. 


\section{RESULTS AND DISCUSSION}

Table 1: Correlation Coefficients

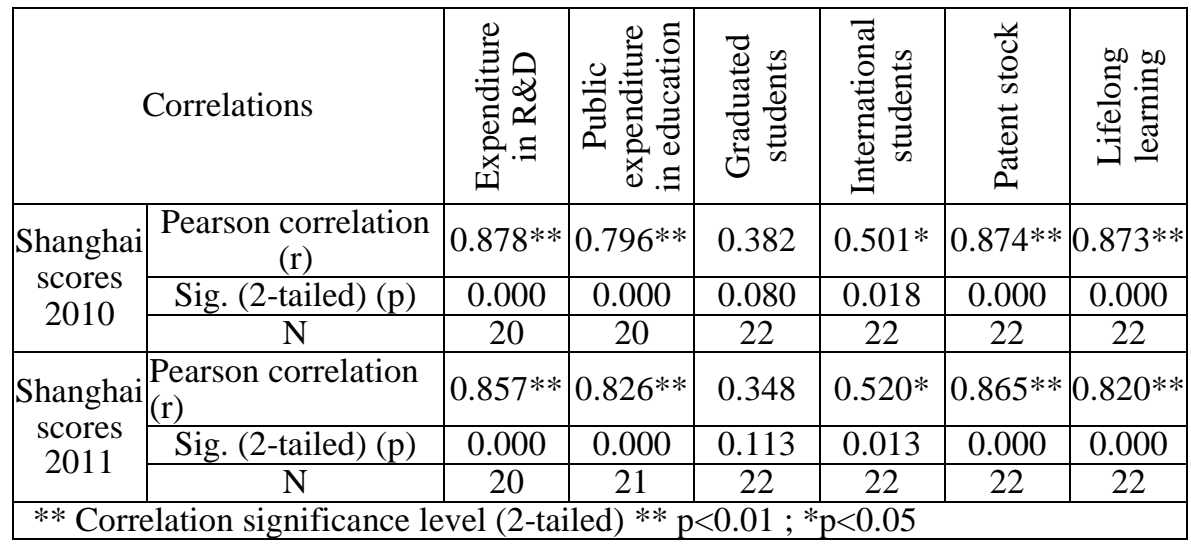

The correlation results (table 1) for 2010, between Shanghai scores and R\&D expenditures, Public Expenditures on Education, Patents, Life Long Learning describe a strong, positive relation between variables, all of them taking values in the interval [0.6:1]. The correlation was significant at 0.01 level (2-tailed). For the Students' international mobilities variable the correlation coefficient has a value 0.51 that placed it at the limit between a moderate and strong positive relationship with the Shanghai score, the correlation significance level being 0.05. Comparing with the situations for the before mentioned variables, the option for this one was to take it into consideration as a moderate correlation. The variable which does not pass the statistical test is Graduated students aged 30-34 years, the p value = 0.08 , which is greater than 0.05 . In this case, there is insufficient evidence to conclude that there is a significant linear relationship, a fact that is revealed also by the last scatter plot (figure 2). 


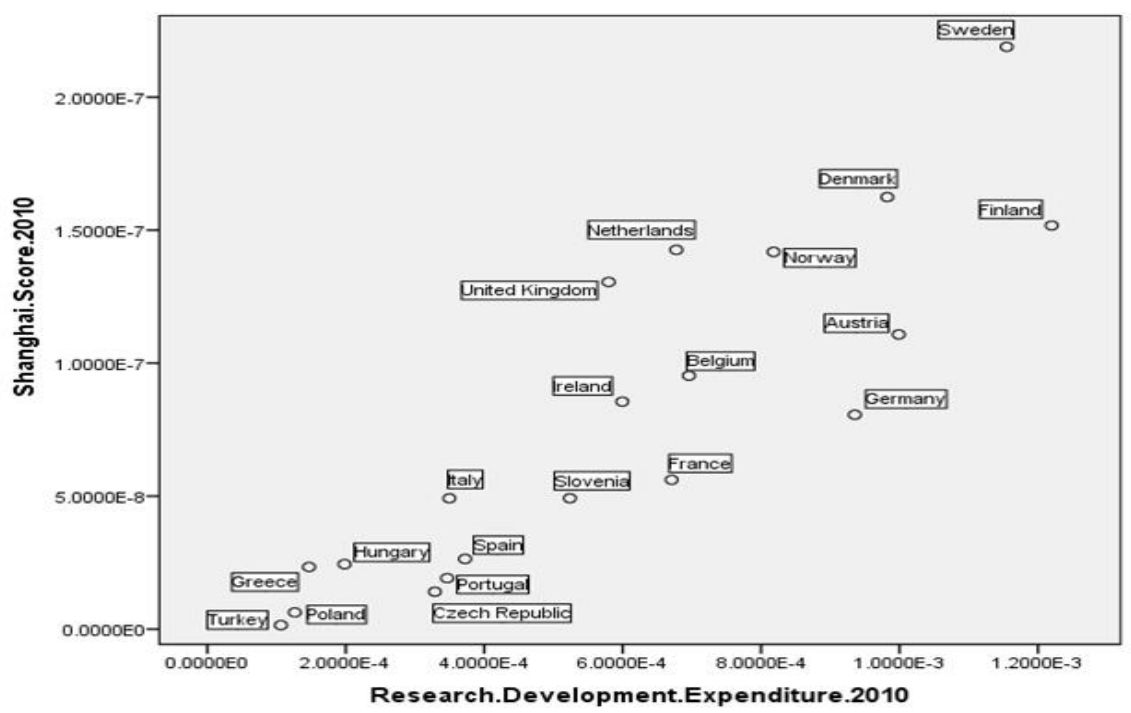

Figure 1: Scatter Plot for the 2010 correlation between EU countries' R\&D expenditure and their Shanghai ranking scores

Correlation results for 2011 are very similar with correlations from 2010, confirming that the conclusions' set for 2010 is correct. The same inconclusiveness is observed for Graduated students, which once again fell the statistical test, with $\mathrm{p}$ value $=0.11$.

As a final result, we can say that the majority of the headline indicators on education and R\&D of the Europe 2020 strategy have a strong positive relationship with university performance measured by scores obtained in the Shanghai Ranking.
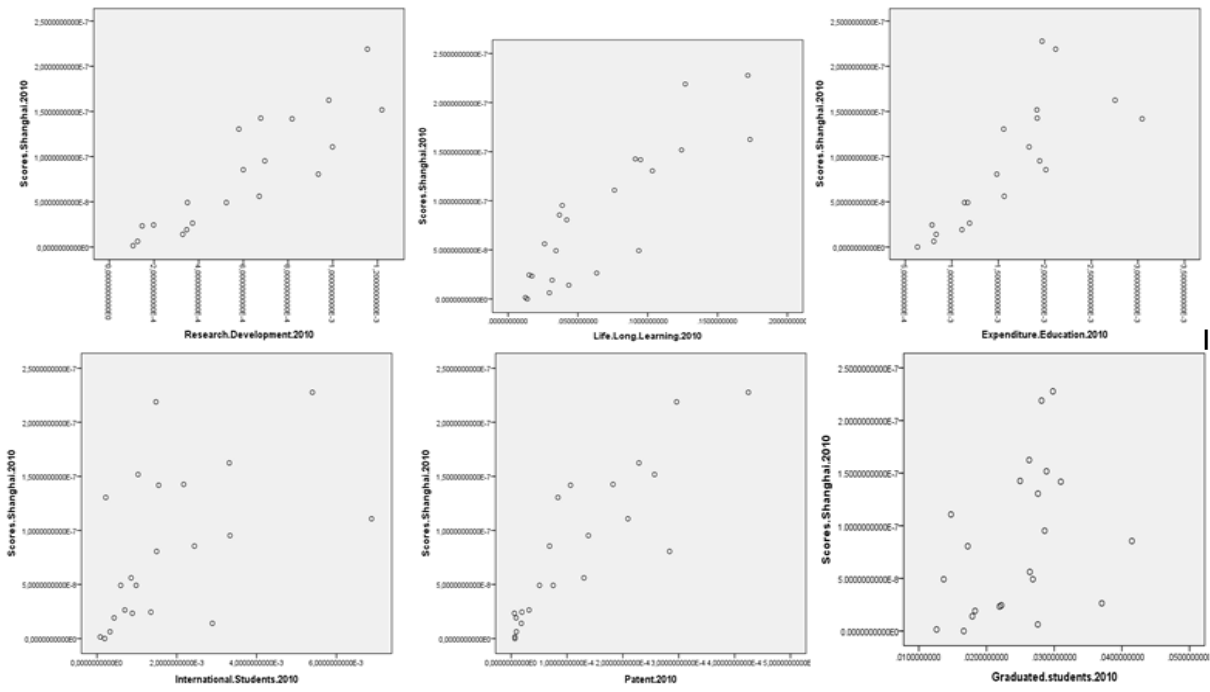

Figure 2: Scatter Plots for 2010 correlations between countries' values of the Europe 2020 indicators and their Shanghai ranking scores 


\section{CONCLUSIONS}

The objective of this paper was to assess whether there is a significant relationship between performance of the universities calculated by scores obtained in a world university ranking (ARWU) and headline indicators set by the strategy of the European Union for achieving modernization of higher education. Our results show there is a strong positive relationship between R\&D Expenditure; Public Expenditure on Education; Patent stock; Life Long Learning indicators and scores obtained by European countries in the Shanghai Ranking.

Without falling into the trap of finding any causal relationship, the above study points to the fact that by following the EU strategies in the field of higher education and research, European countries have an increased chance to also increase their scores in the Shanghai 500 ranking.

Two possible continuation scenarios can be foreseen to further refine the results of this study, beside the already mentioned extension to the entire set of 2020 indicators: one is to continue in a chronological approach and identify changes in correlation profile going from year to year, using the same variables, while the other one is to perform similar studies on other world university rankings. Both directions could yield information useful for the strategic piloting of higher education systems in Europe.

Among the limitations of this method, we reiterate the fact that the choices for the studied variables have been limited by the available data and that, once a correlation is discovered, investigating it further, to establish if there is indeed a causality and in which way countries could act upon it, is a considerable difficulty.

\section{REFERENCES}

CWCU. (2013). ARWU Methodology 2013. Retrieved June 2015, from Academic Ranking of World Univ. (ARWU): http://www.shanghairanking.com

Cybermetrics Lab. (2015). Ranking Web of Universities. Retrieved July 2015, from http://www.webometrics.info/

Dill, D.D., Soo, M. (2005). Academic quality, league tables, and public policy: A cross-national analysis of university ranking systems. Higher Education, 49(4), pp. 495533.

EC (European Commission). (2010). Europe 2020 A European strategy for smart, sustainable and inclusive growth.

EC (European Commission). (2013). Research and Innovation performance in EU Member States and Associated countries.

EC-CHERPA. (2014). U-Multirank. Retrieved August 2015, from http://www.umultirank.eu/

Eurostat. (2015a). Europe 2020 indicators - education. Retrieved July 2015, from EUROSTAT: http://ec.europa.eu/eurostat/statisticsexplained/index.php/Europe_2020_indicators_-_education 
Eurostat. (2015b). Europe 2020 indicators - $R \& D$. Retrieved July 2015, from EUROSTAT: $\quad$ http://ec.europa.eu/eurostat/statistics-explained/index.php/ File:Indicators_and_concepts_on_the_R\%26D_target_Fig2_1.png

Hardeman, S., Van Roy, V., \& Vertesy, D. (2014). Measuring research excellence in the EU - rationale, components, and implications. Retrieved September 2015, from https://ecpr.eu/Filestore/PaperProposal/2cd2e381-6e28-4a2e-8e7a-51babdb4a186.pdf

Hazelkorn, E. (2015). Rankings and the Reshaping of Higher Education: The Battle for World-Class Excellence (2nd ed.). Palgrave Macmillan.

QS. (2015). QS World University Rankings: Methodology. Retrieved September 2015, from QS TOPUNIVERSITIES: http://www.topuniversities.com

Shin, J.C. \& Toutkoushian, R.K. (2011). The Past, Present, and Future of University Rankings in J.C. Shin, R.K. Toutkoushian, U. Teichler (Eds)., University Ranking. Theoretical Basis, Methodology and impact on Global Higher Education (pp. 1-18). Springer.

The Guardian. (2013). World university rankings: how much influence do they really have. Retrieved August 2015, from http://www.theguardian.com/

Times Higher Education. (2015). THE World University Ranking. Retrieved August 2015, from https://www.timeshighereducation.com/

UNESCO. (2015). Educating-for-a-sustainable-future. Retrieved July 2015, from http://www.unesco.org/new/en/rio-20/educating-for-a-sustainable-future/ 